\title{
Fontes fosfatadas e acidez do solo na produção de mudas de Theobroma grandiflorum
}

O cupuaçu (Theobroma grandiflorum) é uma planta nativa da Amazônia brasileira pertencente à família Malvaceae. É bastante apreciada na região norte do Brasil, principalmente pelo seu sabor e aroma de sua polpa. O objetivo trabalho foi avaliar o comportamento de mudas de cupuaçu (Theobroma grandiflorum) sob adubação fosfatada e correção da acidez do solo. O experimento foi conduzido em casa de vegetação localizada no Instituto de Ciências Agrárias (ICA), Área de Ciências do solo, da Universidade Federal Rural da Amazônia (UFRA), município de Belém (PA). Utilizou-se o delineamento experimental inteiramente casualizado, em esquema fatorial, $3 \times 2$, distribuídos em 4 repetições, perfazendo um total de 24 unidades experimentais. Os fatores foram: Adubação fosfatada (Superfosfato triplo, superfosfato simples e yoorin); e correção do solo (com e sem calagem). Nas adubações fosfatadas foram aplicados $0,06 \mathrm{~g} / \mathrm{planta}$ de superfosfato triplo com 43\% de P2O5; 0,15 g/planta Yoorin Master $17 \%$ de P2O5 e 0,13 g/planta superfosfato simples $20 \%$ P2O5. Afim de suprir as necessidades nutricionais da planta, também foram aplicados $0,07 \mathrm{~g} /$ planta de ureia e cloreto de potássio. A correção do solo foi realizada pelo método de saturação de base, elevando as bases trocáveis do solo a 60\%, aplicando-se $8.1 \mathrm{~g}$ de calcário dolomítico com o PRNT $92 \%$, por unidade experimental. As variáveis de resposta avaliadas foram: Altura da planta (AP), diâmetro do caule (DC), número de folhas (NF), área foliar (AF), massa verde de folha (MVF), massa seca de folha (MSF), massa verde de raiz (MVR), massa seca de raiz (MSR), comprimento de raiz (CR). A combinação das adubações fosfatadas e calagem propicia os melhores resultados para as mudas do cupuaçuzeiro. O termofosfato Yoorin com ou sem correção promove resultados satisfatório para a produção de mudas de cupuaçuzeiro. $\mathrm{O}$ Superfosfato simples promove resultados satisfatórios em relação a fitometria das mudas de cupuaçuzeiro com e sem correção do solo.

\section{Phosphate sources and soil acidity in seedling production of Theobroma Grandiflorum}

Cupuaçu (Theobroma grandiflorum) is a plant native to the Brazilian Amazon belonging to the Malvaceae family. It is greatly appreciated in the northern region of Brazil, mainly for its flavor and aroma of its pulp. The objective of this work was to evaluate the behavior of cupuaçu (Theobroma grandiflorum) seedlings under phosphate fertilization and soil acidity correction. The experiment was conducted in a greenhouse located at the Institute of Agrarian Sciences (ICA), Soil Science Area, Federal Rural University of Amazonia (UFRA), Belém (PA). A completely randomized experimental design in a $3 \times 2$ factorial scheme was used, distributed in 4 replications, making a total of 24 experimental units. The factors were: phosphate fertilization (triple superphosphate, simple superphosphate and yoorin); and soil correction (with and without liming). Phosphate fertilizers were applied $0.06 \mathrm{~g} /$ plant triple superphosphate with $43 \% \mathrm{P} 2 \mathrm{O} 5 ; 0.15 \mathrm{~g} / \mathrm{plant}$ Yoorin Master $17 \%$ P2O5 and $0.13 \mathrm{~g} /$ plant single superphosphate $20 \%$ P2O5. In order to meet the nutritional needs of the plant, $0.07 \mathrm{~g} /$ plant of urea and potassium chloride were also applied. Soil correction was performed by the base saturation method, raising the exchangeable soil bases to $60 \%$, applying $8.1 \mathrm{~g}$ of dolomitic limestone with the PRNT 92\%, per experimental unit. The response variables evaluated were: plant height (AP), stem diameter (DC), leaf number (NF), leaf area (AF), green leaf mass (MVF), dry leaf mass (MSF), green root mass (MVR), dry root mass (MSR), root length (CR). The combination of phosphate fertilizers and liming provides the best results for cupuaçuzeiro seedlings. Yoorin thermophosphate with or without correction promotes satisfactory results for the production of cupuaçuzeiro seedlings. Simple superphosphate promotes satisfactory results regarding the phytometry of cupuaçuzeiro seedlings with and without soil correction.

Keywords: Thermophosphate; P2O5; Phosphorus; Liming.

Topic: Uso de Recursos Naturais

Reviewed anonymously in the process of blind peer
Received: 02/12/2020 Approved: 21/02/2021
Francisco José Lima de Souza (iD

Universidade Federal Rural da Amazônia, Brasil http://lattes.cnpq.br/8134872514883156 http://orcid.org/0000-0002-1289-414X

franciscosouzacr33@gmail.com

Jessivaldo Rodrigues Galvão (iD

Universidade Federal Rural da Amazônia, Brasil http://lattes.cnpq.br/0013591065769741 http://orcid.org/0000-0003-4242-6555 jessigalvao50@gmail.com

Thiago Costa Viana

Universidade Federal Rural da Amazônia, Brasil http://lattes.cnpq.br/2173828234634124

http://orcid.org/0000-0002-6688-676X thiagocostaaa19@gmail.com
Mauro Junior Borges Pacheco (iD) Universidade Federal Rural da Amazônia, Brasil http://lattes.cnpq.br/0756046215703468 http://orcid.org/0000-0001-6024-7054 mauro.jr720@gmail.com

Leonardo de Almeida Oliveira

Universidade Federal Rural da Amazônia, Brasil http://lattes.cnpq.br/8171296454284490 leonardoaaloliveira@gmail.com

Gabriela Vilhena De Almeida (it

Universidade Federal Rural da Amazônia, Brasil http://lattes.cnpq.br/1923584857795627 http://orcid.org/0000-0001-5712-8062 gabrielaalmeida16@hotmail.com
Andreza Mayra Baena Souza de Jesus (iD) Universidade Federal Rural da Amazônia, Brasil http://lattes.cnpq.br/3991687755108607 http://orcid.org/0000-0001-7638-2920 andreza.baena@gmail.com

\section{Larissa Matos Lima (iD}

Universidade Federal Rural da Amazônia, Brasil http://lattes.cnpq.br/7322691238244021 http://orcid.org/0000-0003-2814-3372 larissamatoslim@gmail.com
Referencing this:

SOUZA, F. J. L.; GALVÃO, J. R.; VIANA, T. C.; PACHECO, M. J. B.; OLIVEIRA, L. A.; ALMEIDA, G. V.; JESUS, A. M. B. S.; LIMA, L. M.. Fontes fosfatadas e acidez do solo na produção de mudas de Theobroma grandiflorum. Nature and Conservation, v.14, n.1, p.141-148, 2021. DOI: $\underline{\text { http://doi.org/10.6008/CBPC2318-2881.2021.001.0016 }}$ 


\section{INTRODUÇÃO}

O cupuaçu (Theobroma grandiflorum) é uma fruta nativa da Amazônia brasileira pertencente à família Malvaceae. É bastante apreciada na região norte do Brasil pelo sabor e aroma de sua polpa, que é utilizada na fabricação de sucos, sorvetes, cremes, geleias, picolés, entre outros (FERREIRA et al., 2009).

A espécie encontra-se implantada, em vários tipos de solos, com predominância nos de baixa fertilidade natural e pouco ainda se conhece sobre as suas exigências nutricionais, entretanto, por ser uma frutífera que se desenvolve bem em condições de semi-sombreamento, especialmente na fase juvenil, pode ser utilizada com sucesso em sistemas agroflorestais.

A produção de mudas com maior vigor acarreta em bom desempenho das plantas em campo, indicado pelo melhor crescimento inicial após o início do cultivo, contribuindo com o aumento da homogeneidade e redução da mortalidade de plantas. Um fator importante relacionado a esta melhoria da qualidade de mudas é o substrato, onde ocorre a emergência e o crescimento inicial das plantas (SOARES et al., 2014).

Os solos da Amazônia brasileira são conhecidos por possuírem elevada acidez e baixa fertilidade. A plantas não adaptadas a essas condições de solo, não conseguem se desenvolver, reduzir as limitações químicas do solo é importante para se ter uma produtividade economicamente viável, e possibilitar um rápido crescimento. As classes predominantes de solos nessa região são os Latossolos e os Argissolos, com argilas de baixa capacidade de troca catiônica e predominância de caulinita (OSAKADA, 2009; VIEIRA et al., 1987).

Apesar das limitações químicas que estes solos apresentam, suas boas características físicas os tornam plenamente agriculturáveis. Visando corrigir a acidez do solo e reduzir efeitos tóxicos de elementos como Al3+, Mn2+ e Fe2+, realiza-se a prática de calagem. Ainda vale destacar que este procedimento eleva os teores de Ca2+ e Mg2+ no solo (RAIJ, 1991; TUCCI, 1996).

A correção apropriada da acidez do solo é extremamente válida para a sustentabilidade no uso do solo, visto que um solo ácido afeta negativamente o desenvolvimento e a produtividade das culturas. Dessa forma, a calagem merece destaque como a prática mais adotada na agricultura para melhorar as propriedades químicas do solo (OLIVEIRA et al., 2010). Poucas práticas agrícolas dão retornos tão elevados como a correção da acidez do solo, no que diz respeito ao aumento da produtividade das culturas (BAMBOLIM et al., 2015).

Além da calagem, é recomendável que se realize a adubação para elevar a fertilidade do solo e permitir um melhor crescimento vegetal. O incremento de fósforo via adubação fosfatada possui função preponderante na fotossíntese, balanço energético, divisão e crescimento celular, respiração, entre outros processos que ocorrem na planta (FREITAS et al., 2013). Tratando-se do potássio, afirma-se que é um nutriente que participa direta ou indiretamente de diversos processos bioquímicos relacionados ao metabolismo de carboidratos, a exemplo da fotossíntese e da respiração, de forma que sua carência implica em uma baixa taxa de crescimento (SIMILI et al., 2010). 
As limitações na disponibilidade de nutrientes tem sido um fator limitante no desenvolvimento das plantas em regiões tropicais. O fósforo comparado aos outros nutrientes, possui baixa disponibilidade na maioria dos solos Brasileiros, dessa forma tem grande relevância e tem merecido maiores atenções (MENDES, 2012). O objetivo trabalho foi avaliar a fitometria de mudas de cupuaçu (Theobroma grandiflorum) sob adubação fosfatada e correção da acidez do solo.

\section{METODOLOGIA}

A O experimento foi conduzido no período de março de 2019 a julho de 2019 em casa de vegetação localizada no Instituto de Ciências Agrárias (ICA), Área de Ciências do solo, da Universidade Federal Rural da Amazônia (UFRA), município de Belém (PA), cujas coordenadas geográficas são: 48o 23’ de longitude Oeste de Greenwich e 10 31' de latitude ao Sul do Equador, com altitude de $16 \mathrm{~m}$.

O solo foi coletado da camada de 0-20 cm de profundidade, em uma área de capoeira, com histórico de 20 anos sem produção. O solo coletado foi encaminhado ao laboratório da UFRA, para determinação das necessidades químicas do solo, seguindo a metodologia proposta pela Embrapa (2009), para posterior aplicação dos tratamentos. A composição química do solo da área experimental encontra-se na Tabela 1.

Tabela 1: Atributos químicos do solo utilizado no experimento, coletado à profundidade de 0-20 cm do perfil do solo (1) extração Mehlich-1; (2) extração $\mathrm{KCl} 1,00 \mathrm{~mol}$ L-1; (3) extração acetato de cálcio 0,05 mol L-1. pH: potencial hidrogeniônico; Corg: carbono orgânico; M.O: teor de matéria orgânica; P: fósforo disponível; K: potássio disponível; Ca2+: cálcio trocável; Mg2+: magnésio trocável; Al3+: alumínio trocável; $\mathrm{H}+\mathrm{Al}$ : acidez potencial.

\begin{tabular}{|c|c|c|c|c|c|c|c|c|c|}
\hline \multicolumn{2}{|l|}{$\mathrm{pH}$} & $\mathrm{C}_{\text {org }}$ & M.O & $\mathrm{P}^{(1)}$ & $\mathrm{K}^{+(1)}$ & $\mathrm{Ca}^{2+(2)}$ & $\mathrm{Mg}^{2+(2)}$ & $\mathrm{Al}^{+3(3)}$ & $\mathrm{H}+\mathrm{Al}$ \\
\hline $\mathrm{H}_{2} \mathrm{O}$ & $\mathrm{KCl}$ & \multicolumn{2}{|c|}{$---\mathrm{g} \mathrm{kg}^{-1}---$} & $\mathrm{mg} \mathrm{dm}^{-3}$ & \multicolumn{5}{|c|}{ 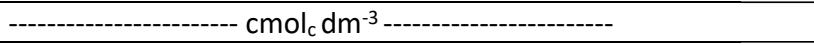 } \\
\hline 4,55 & 3,23 & 9,29 & 16,02 & 23,69 & 0,02 & 0,5 & 1,00 & 0,94 & 6,08 \\
\hline
\end{tabular}

Utilizou-se o delineamento experimental inteiramente casualizado, em esquema fatorial, $3 \times 2$, distribuídos em 4 repetições, perfazendo um total de 24 unidades experimentais. Os fatores foram: Adubação fosfatada (Superfosfato triplo, superfosfato simples e yoorin); e correção do solo (com e sem calagem). Os tratamentos foram distribuídos na seguinte forma (Tabela 2).

Tabela 2: Distribuição dos tratamentos.

\begin{tabular}{l|l}
\hline Correção do solo & Adubos fosfatados \\
\hline Com calagem & Superfosfato triplo \\
Sem calagem & Superfosfato triplo \\
Com calagem & Superfosfato simples \\
Sem calagem & Superfosfato simples \\
Com calagem & Yoorin (Fosfato Natural) \\
Sem calagem & Yoorin (Fosfato Natural) \\
\hline
\end{tabular}

Nas adubações fosfatadas foram aplicados 0,06 g/planta de superfosfato triplo com 43\% de P2O5; 0,15 g/planta Yoorin Master 17 \% de P2O5 e 0,13 g/planta superfosfato simples 20 \% P2O5, calculadas de acordo com as análises iniciais do solo realizada.

Afim de suprir as necessidades nutricionais da planta, também foram aplicados 0,07 g/planta de ureia e cloreto de potássio. A correção do solo foi realizada pelo método de saturação por base, elevando as bases trocáveis do solo a 60\%, aplicando-se 8,1 g de calcário dolomítico (PRNT 92 \%), por unidade experimental, realizadas por um período de 30 dias antes do transplantio. O calcário foi aplicado no solo e, após 30 e 60 
dias de reação, realizou-se análise de pH para determinar a acidez ativa, cujos resultados foram 6,38 e 6,93 respectivamente.

As mudas de cupuaçuzeiro utilizadas no experimento, foi da cultivar BRS Carimbó, cedidas pela Empresa Brasileira de Pesquisa Agropecuária (EMBRAPA). É um clone produzido pela própria empresa, resistente à vassoura-de-bruxa, principal doença de acomete a cultura, cujo agente etiológico é o Moniliophthora perniciosa. $\mathrm{O}$ experimento iniciou-se com a alocação das plântulas em sacos de polietileno com capacidade de $5 \mathrm{dm} 3$, preenchidos com solo, cultivadas por um período de cinco meses.

Completado esse período, foram coletados os dados resultantes aos tratamentos aplicados. As variáveis de resposta avaliadas foram: Altura da planta (AP), diâmetro do caule (DC), número de folhas (NF), área foliar (AF), massa verde de folha (MVF), matéria seca de folha (MSF), matéria verde de raiz (MVR), matéria seca de raiz (MSR), comprimento de raiz (CR). Os resultados foram tabulados no Excel 2013, e posteriormente submetidos à análise de variância e, quando significativo, as médias foram comparadas pelo teste de Tukey ao nível de 5\% de significância. O software computacional SISVAR foi utilizado nas análises estatísticas (FERREIRA, 2011).

\section{RESULTADOS E DISCUSSÃO}

Não foram observados efeitos significativos para as variáveis altura da planta (AP), diâmetro do caule (DC) e número de folhas em relação aos tratamentos, de maneira isolada como também em suas interações. Para área foliar (AF), matéria verde de folha (MVF) e matéria seca de folha (MSF) os efeitos foram influenciados significativamente pelos tratamentos tanto de forma isolada quando na interação entre os mesmos. Para massa verde de raiz (MVR) e massa seca de raiz (MSR), não foram observados efeitos significativos apenas para a correção do solo, já para o crescimento de raiz (CR) efeitos significativos foram encontrados apenas na correção do solo (Tabela 3).

Tabela 3: Resumo da análise de variância para os tratamentos com as fontes fosfatadas e correção da acidez do solo em relação às variáveis, altura da planta (AP), diâmetro do caule (DC), área foliar (AF), número de folhas (NF), massa verde de folha (MVF), massa seca de folha (MSF), massa verde de raiz (MVR), massa seca de raiz (MSR) e Crescimento de raiz (CR) $-\left({ }^{* *}\right)$ significativo ao nível de $5 \%$ de probabilidade, (ns) não significativo ao nível de $5 \%$ de probabilidade.

\begin{tabular}{lllllllllll}
\hline FONTES DE VARIAÇÃO & $\mathrm{G} . \mathrm{L}$ & $\mathrm{AP}$ & $\mathrm{DC}$ & $\mathrm{AF}$ & $\mathrm{NF}$ & $\mathrm{MVF}$ & $\mathrm{MSF}$ & $\mathrm{MVR}$ & $\mathrm{MSR}$ & $\mathrm{CR}$ \\
\hline Fonte Fosfatada & 2 & $\mathrm{~ns}$ & $\mathrm{~ns}$ & $* *$ & $\mathrm{~ns}$ & $* *$ & $* *$ & $* *$ & $* *$ & $\mathrm{~ns}$ \\
Correção & 1 & $\mathrm{~ns}$ & $\mathrm{~ns}$ & $* *$ & $\mathrm{~ns}$ & $* *$ & $* *$ & $\mathrm{~ns}$ & $\mathrm{~ns}$ & $* *$ \\
Fonte X Correção & 2 & $\mathrm{~ns}$ & $\mathrm{~ns}$ & $* *$ & $\mathrm{~ns}$ & $* *$ & $* *$ & $* *$ & $* *$ & $\mathrm{~ns}$ \\
CV (\%) & - & 9,57 & 9,69 & 15,84 & 16,62 & 13,05 & 8,8 & 10,79 & 11,33 & 8,21 \\
\hline
\end{tabular}

Os maiores valores de área foliar $(289,08 \mathrm{~cm} 2)$ foram observados com a aplicação do superfosfato simples, de maneira isolada, sem efeitos significativos quando da correção do solo. As fontes superfosfato triplo e Yoorin aplicadas de maneira isolada responderam negativamente, obtendo os menores índices de área foliar (Figura 1). Nogueira et al. (1977), trabalhando com as fontes superfosfato triplo, hiperfosfato, termofosfato e apatita-de-araxá, em plantas de soja, verificaram não haver diferenças estatística, entre essas fontes, para a variável área foliar. No experimento, apesar de ser realizado em plantas de cupuaçuzeiros, os efeitos das fontes fosfatadas também foram constatados, indicando a importância do conhecimento do 
produto a ser aplicado visando maior rendimento da planta.

Nota-se que a produção de MVF, apenas a fonte SFS não foi influenciada pela calagem. As demais, ou seja, SFT e Yoorin foram diretamente afetadas, com resultados maiores após a correção da acidez do solo (Figura 2). Efeitos significativos com a aplicação da fonte SFS, também foram obtidos por Alfaia et al. (2004) os quais relatam ser o fósforo o principal nutriente que possivelmente limitaria o desenvolvimento da cultura do cupuaçu. Os mesmos autores, em experimento com plantas de cupuaçuzeiro, verificaram que a calagem aumentou o teor de $\mathrm{Ca}$ e $\mathrm{Mg}$ e diminuiu a concentração do Al trocável no solo, aliados as fontes fosfatadas, promoveram um bom desenvolvimento da cultura, confirmando a importância desse nutriente.

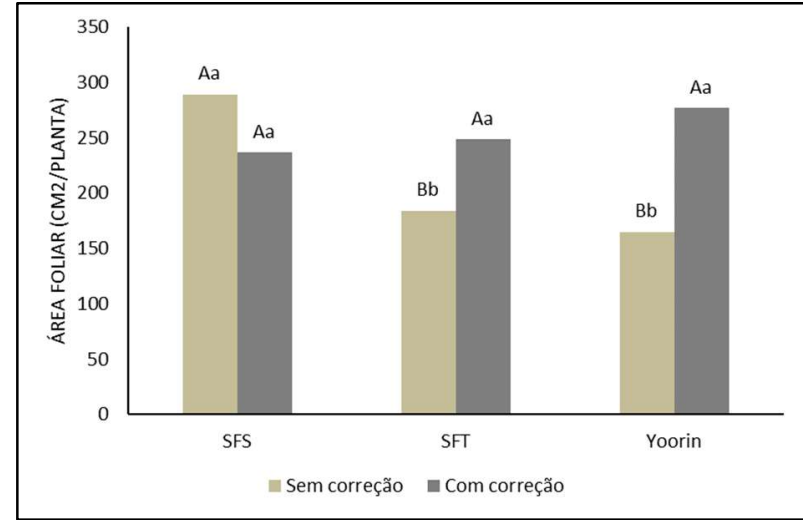

Figura 1: Área foliar (cm2/planta) das plantas de cupuaçuzeiros em função da aplicação das fontes fosfatadas e correção do solo - letras maiúsculas comparam as fontes entre as correções e minúsculas comparam as correções em cada fonte.

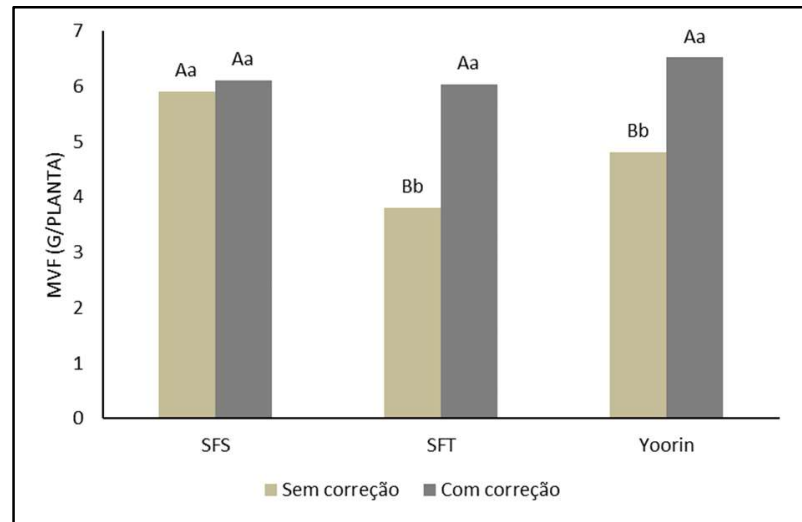

Figura 2: Produção de massa verde de folha em gramas em função das fontes fosfatadas e correção do solo -

letras maiúsculas comparam as fontes entre as correções e minúsculas comparam as correções em cada fonte.

Para a massa seca das folhas, foi verificado não haver diferenças estatísticas entre os tratamentos, com exceção do superfosfato triplo, aplicado isoladamente, que obteve a maior produção quando foi realizado a calagem.

Os maiores resultados nessa produção de MSF foram obtidos na aplicação de Yoorin com a correção do solo. Fernandes e et al. (2003), citam que a aplicação de calcário eleva os teores de Ca e Mg, reduz ou elimina o Al trocável e aumenta as cargas negativas nesses solos, consequentemente aumentando a disponibilidade de nutrientes, entre os quais o P. No caso específico desse nutriente, a magnitude de recuperação e sua utilização pelas plantas são regidas por vários fatores, entre os quais estão a própria planta e o tipo de fosfato empregado (SOUZA, 2003).

O Yoorin, sendo termofosfato magnesiano, possui também propriedade alcalina, isto é, devido aos seus teores de $\mathrm{CaO}(28 \%)$ e de $\mathrm{MgO}(11 \%)$ na forma de silicato, o mesmo eleva os valores de cálcio e de magnésio no solo, e consequentemente, a soma de bases, portanto, a saturação por bases. Isto é de extrema importância, tendo-se em vista que, em áreas com culturas exigentes em Ca e Mg como as de frutíferas, o uso desse insumo facilitaria o manejo mais adequado da fertilidade do solo (SOUZA, 2003).

A MVR foi influenciada pela aplicação do Yoorin, com adição do calcário, alcançando maior produção, sendo a menor quando aplicado SFS com correção do solo (Figura 4). O termofosfato Yoorin além de conter $P$, possuem sua composição em outros elementos essenciais ao desenvolvimento de plantas. Os 
termofosfatos são fertilizantes fosfatados insolúveis em água e com alta solubilidade em ácido cítrico, essa característica traz grande interesse quando comparada à solubilidade dos fosfatos acidulados. Com a acidez natural da solução do solo, possibilita uma liberação gradativa do ânion fosfato dos termofosfatos, e, por conseguinte, menor retenção/fixação do $\mathrm{P}$ às partículas do solo, possibilitando maior absorção pelas plantas (FASSBENDER, 1987). A atuação desse fertilizante pode justificar os resultados obtidos no experimento, visto que o termofosfato Yoorin possui a capacidade de alterar o $\mathrm{pH}$ do solo, proporcionando maior massa radicular nas mudas de cupuaçuzeiro (SILVA et al., 2011).

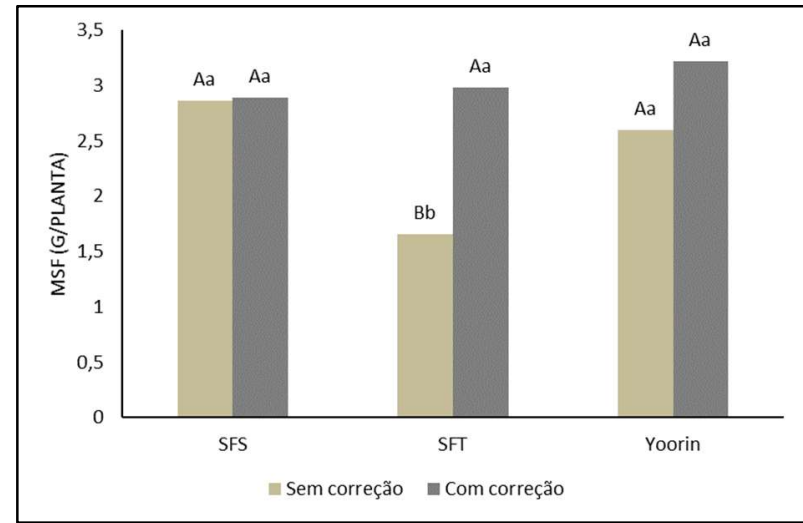

Figura 3: Produção média de massa seca de folha em gramas em função das fontes fosfatadas e correção do solo - letras maiúsculas comparam as fontes entre as correções e minúsculas comparam as correções em cada fonte.

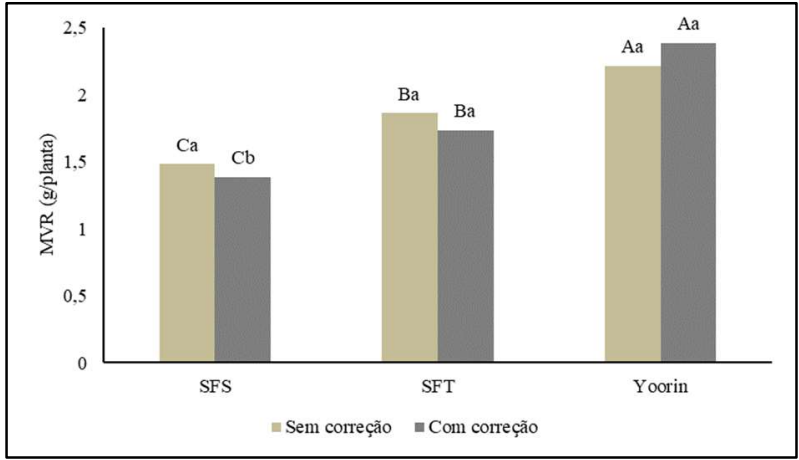

Figura 4: Produção de massa verde de raiz em gramas em função das fontes fosfatadas e correção do solo letras maiúsculas comparam as fontes entre as correções e minúsculas comparam as correções em cada fonte.

A MSR também foi influenciada diretamente pela aplicação de Yoorin com o calcário, e estatisticamente igual a fonte SFT sem correção. Para as demais fontes de fósforo os resultados foram menores com e sem correção, sendo a menor quando aplicado SFS sem correção (Figura 5). O fósforo é responsável pela rápida formação e crescimento das raízes (DECHEN et al., 2007) importante para um rápido estabelecimento das mudas quando transferidas do viveiro para o campo (PRADO, 2008). Entretanto, notase que, mesmo havendo maior produção de MSR na fonte Yoorin, ela não se diferenciou da fonte SFT, indicando que pode ter havido uma superestimação, pois, para esse intervalo de tempo de condução do experimento, e ainda na presença de calagem, esse resultado não era esperado.

Na variável CR foi significativo somente para correção alcançando o maior valor no tratamento sem a aplicação do corretivo. É possível que, com a calagem o pH se elevou diminuído o teor de Al trocável e aumentado a concentração de Ca e Mg trocáveis no solo com isso, a raiz não necessitou maior crescimento em busca de nutrientes. Possivelmente, em razão da aplicação localizada dos adubos fosfatados na superfície do solo, embora as plantas tenham sido cultivadas em sacos plásticos, e possuírem o sistema radicular restrito à um volume pequeno de solo e mesmo mantendo constante a umidade, o principal mecanismo de contato do íon H2PO4 é a difusão, além de possuir baixa mobilidade, reduzindo o contato do P com todo o volume de solo calcareado (TEIXEIRA et al., 2011). 


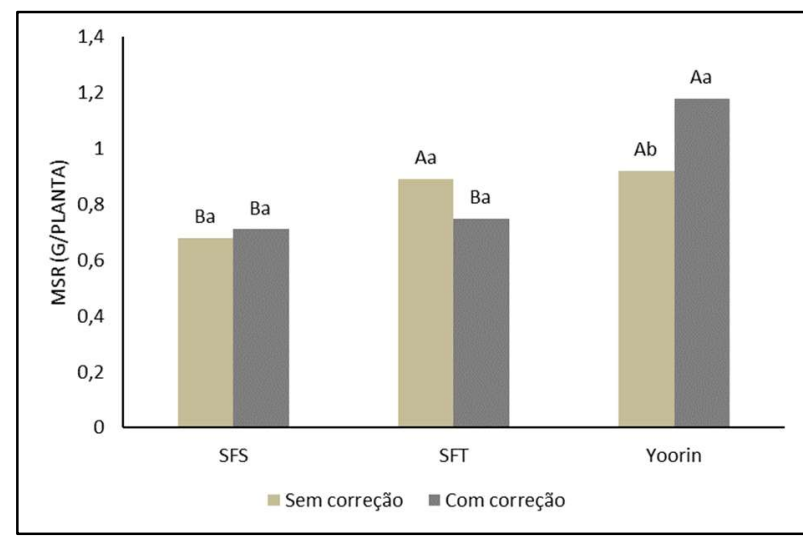

Figura 5: Produção média de massa seca de raiz em gramas em função das fontes fosfatadas e correção do solo - letras maiúsculas comparam as fontes entre as correções e minúsculas comparam as correções em cada fonte.

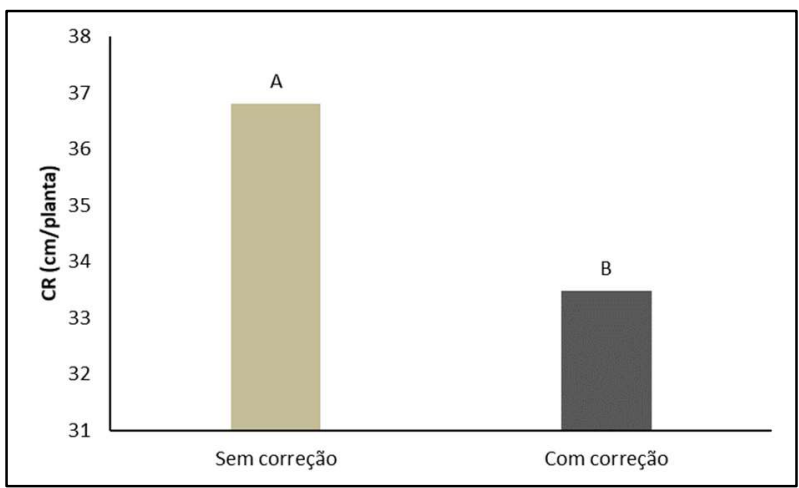

Figura 6: Comprimento de raiz em cm/planta em função das fontes fosfatadas e correção do solo. Letras maiúsculas comparam as fontes entre as correções.

\section{CONCLUSÕES}

A combinação das adubações fosfatadas e calagem propicia bons resultados para as mudas do cupuaçuzeiro. O termofosfato Yoorin com ou sem correção prove resultados satisfatório para a produção de mudas de cupuaçuzeiro. O Superfosfato simples promove resultados positivos em relação a fitometria das mudas de cupuaçuzeiro com e sem correção do solo.

\section{REFERÊNCIAS}

ALFAIA, S. S.; AYRES, I. C. A.. Efeito de doses de nitrogênio, fósforo e potássio em duas cultivares de cupuaçu, com e sem sementes, na região da Amazônia central. Revista Brasileira Fruticultura, Jaboticabal, v.26, n.2, p.320-325, 2004.

BAMBOLIM, A.; CAIONE, G.; SOUZA, N.F.; SEBEN-JUNIOR, G. F.; FERBONINK, G. F.. Calcário líquido e calcário convencional na correção da acidez do solo. Revista de Agricultura Neotropical, Cassilândia, v.2, n.3, p.34-38, 2015.

DECHEN, A. R.; NACHTIGALL, G. R.. Elementos requeridos à nutrição de plantas. In: NOVAIS, R. F.; ALVAREZ, V. V. H.; BARROS, N. F.; FONTES, R. L. F.; CANTARUTTI, R. B.; NEVES, J. C. L.. Fertilidade do Solo. Viçosa: UFV, 2007. p.92-132.

EMBRAPA. Empresa Brasileira de Pesquisa Agropecuária. Manual de análises químicas de solos, plantas e fertilizantes. 2 ed. Brasília: EMBRAPA - Informação Tecnológica, 2009.

FASSBENDER, H. W.. Química de suelos con énfasis en suelos de América Latina. 2 ed. San José: Instituto Interamericano de Cooperação para Agricultura, 1987.

FERNANDES, A. R.; CARVALHO, J. G.; MELO, P. C.. Efeito do fósforo e do zinco sobre o crescimento de mudas do cupuaçuzeiro (Theobroma grandifrolum Schum.). Cerne, v.9, p.221-230, 2003.

FERREIRA, D. F.. Sisvar: A computer statistical analysis system. Ciência e Agrotecnologia, Lavras, v.35, n.6, p.10391042, 2011.
FERREIRA, M. G. R.; ROCHA, R. B.; GONÇALVES, E. P.; ALVES, E. U.; RIBEIRO, G. D.. Influência do substrato no crescimento de mudas de cupuaçu (Theobroma grandiflorum Schum.). Acta Scientiarum Agronomy, v.31, n.4, p.677-681, 2009.

FREITAS, R. M. O.; NOGUEIRA, N. W.; PINTO, J. R. S.; TOSTA, M. S.; DOMBROSKI, J. L. D.. Fertilizante fosfatado no desenvolvimento inicial de mudas de pinheira. Bioscience Journal, Uberlândia, v.29, n.2, p.319-327, 2013.

MENDES, F. F.. Controle genético da eficiência no uso de fósforo em milho tropical. Lavras: UFLA, 2012.

NOGUEIRA, S. S. S.; BATAQLIA, O. C.; MASCARENHAS H. A. A.. Efeitos de fontes e doses de fósforo sobre área foliar e produção de grãos de soja. Bragantia, v.27, n.7, p.459-470, 1977.

OLIVEIRA, C. M. R.; PASSOS, R. R.; ANDRADE, F. V.; REIS, E. F.; STURM, G. M.; SOUZA, R. B.. Corretivo da acidez do solo e níveis de umidade no desenvolvimento da cana-de-açúcar. Revista Brasileira de Ciências Agrárias, Recife, v.5, n.1, p.2531, 2010.

OSAKADA, A.. Desenvolvimento inicial de sangue-de-dragão (Croton lechleri Müll. Arg.) sob diferentes classes de solos, corretivos e níveis de luminosidade na Amazônia central. Dissertação (Mestrado) - Instituto Nacional de Pesquisas da Amazônia, Manaus, 2009.

PRADO, R. M.. Nutrição de plantas. São Paulo: UNESP, 2008.

RAIJ, B. V.. Fertilidade do solo e adubação. Piracicaba: Ceres, 1991. 
SILVA, T. A. F.; TUCCI, C. A. F.; SANTOS, J. Z. L.; BATISTA, I. M. P.; MIRANDA, J. F.; SOUZA, M. M.. Calagem e adubação fosfatada para a produção de mudas de Swietenia macrophylla. Floresta, v.41, n.3, p.459-470. 2011.

SIMILI, F. F.; GOMIDE, C. A. M.; MOREIRA, A. L.; REIS, R. A.; LIMA, M. L. P.; PAZ, C. C. P.. Respostas do híbrido de sorgosudão às adubações nitrogenada e potássica: características estruturais e produtivas. Ciência \& Agrotecnologia, v.34 n.1, p.87-94, 2010.

SOARES, E. R.; BASEGGIO, E. A.; SENA, S. P.; PEREIRA, M. D.. Emergência e desenvolvimento inicial de plântulas de cupuaçu em substrato enriquecido com biofertilizante. Revista Brasileira de Agroecologia, v.9, n.1, p.176-184, 2014.
SOUZA, E. C. A.. Uso agronômico do termofosfato no Brasil. 2 ed. Poços de Caldas: Fertilizantes Mitsui, 2003.

TEIXEIRA, P. C.; MACEDO, S. T.. Calagem e fósforo para a formação de mudas de biribazeiro. Revista de Ciências Agrárias, v.54, n.3, p.259-266, 2011.

TUCCI, C. A. F.. Seleção de métodos de laboratório para estimativa da necessidade de calagem em alguns solos da Amazônia. Revista da Universidade do Amazonas, v.8, n.1-2, p.1-19, 1996.

VIEIRA, L. S.; SANTOS, P. C. T. C.. Amazônia: seus solos e outros recursos naturais. São Paulo: Ceres, 1987.

A CBPC - Companhia Brasileira de Produção Científica (CNPJ: 11.221.422/0001-03) detém os direitos materiais desta publicação. Os direitos referem-se à publicação do trabalho em qualquer parte do mundo, incluindo os direitos às renovações, expansões e disseminações da contribuição, bem como outros direitos subsidiários. Todos os trabalhos publicados eletronicamente poderão posteriormente ser publicados em coletâneas impressas sob coordenação da Sustenere Publishing, da Companhia Brasileira de Produção Científica e seus parceiros autorizados. Os (as) autores (as) preservam os direitos autorais, mas não têm permissão para a publicação da contribuição em outro meio, impresso ou digital, em português ou em tradução. 